\title{
Bacterial thiol oxidoreductases - from basic research to new antibacterial strategies
}

\author{
Katarzyna M. Bocian-Ostrzycka ${ }^{1}$ - Magdalena J. Grzeszczuk ${ }^{1}$ • \\ Anna M. Banaś ${ }^{1}$. Elżbieta Katarzyna Jagusztyn-Krynicka ${ }^{1}$
}

Received: 6 February 2017 /Revised: 3 April 2017 / Accepted: 4 April 2017 /Published online: 13 April 2017

(C) The Author(s) 2017. This article is an open access publication

\begin{abstract}
The recent, rapid increase in bacterial antimicrobial resistance has become a major public health concern. One approach to generate new classes of antibacterials is targeting virulence rather than the viability of bacteria. Proteins of the Dsb system, which play a key role in the virulence of many pathogenic microorganisms, represent potential new drug targets. The first part of the article presents current knowledge of how the Dsb system impacts function of various protein secretion systems that influence the virulence of many pathogenic bacteria. Next, the review describes methods used to study the structure, biochemistry, and microbiology of the Dsb proteins and shows how these experiments broaden our knowledge about their function. The lessons gained from basic research have led to a specific search for inhibitors blocking the Dsb networks.
\end{abstract}

Keywords Dsb (disulfide bond) · Virulence · Secretion system $\cdot$ Antibacterial drugs

\section{Introduction}

Cysteine residues play a crucial role in post-translational modification that guarantees correct protein folding. The oxidation reaction between two cysteine thiol groups, leads to formation of a disulfide bond. While disulfide bonds can form spontaneously in the presence of atmosphere, the reaction is slow.

Elżbieta Katarzyna Jagusztyn-Krynicka

kjkryn@biol.uw.edu.pl

1 Department of Bacterial Genetics, Institute of Microbiology, Faculty of Biology, University of Warsaw, Miecznikowa 1,

02-096 Warsaw, Poland
Instead, in vivo disulfide bond formation is catalyzed by a range of proteins, the thiol oxidoreductases of the Dsb (disulfide bond) system. The first Dsb protein discovered was Escherichia coli DsbA (Bardwell et al. 1991). Since then, the Dsb protein network of E. coli (EcDsb) has been wellcharacterized through a combination of microbiological, biochemical, biophysical, and proteomic approaches. Several excellent review papers presenting the details of the process have recently been published (Berkmen 2012; Cho and Collet 2013; Denoncin and Collet 2013; Kadokura and Beckwith 2010). To briefly summarize, in E. coli, the activity of the periplasmic and soluble monomeric DsbA generates disulfides in a consecutive manner on polypeptide chains that are translocated into the periplasm, whereas dimeric periplasmic EcDsbC is responsible for shuffling improperly formed disulfides. Correct functioning of the EcDsbA and EcDsbC is ensured by two inner membrane proteins $(\mathrm{EcDsbB}$ and EcDsbD, respectively). EcDsbB converts reduced EcDsbA back to the oxidized form by transporting electrons to either ubiquinone or menaquinone. The integral membrane protein $\mathrm{EcDsbD}$ keeps EcDsbC in the reduced form by catalyzing the transfer of electrons from the cytoplasm to the periplasm.

Outside of E. coli, other bacteria have extremely diverse Dsb systems, both in terms of the numbers of proteins playing a role in the introduction of disulfide bonds, and in their structures and interactions. We still do not fully understand why some bacterial species need incredibly complicated sets of Dsb proteins, while others thrive with exceedingly simple systems. Significant differences in Dsb systems have been observed between species of the same genus as well as between strains of the same species (Bocian-Ostrzycka et al. 2015a; Grimshaw et al. 2008; Lin et al. 2009). A growing number of sequenced bacterial genomes makes it difficult to enumerate all the Dsb systems described so far. Some were depicted in two review papers published some years ago (Heras et al. 
2009; Lasica and Jagusztyn-Krynicka 2007). The number of Dsbs that are oxidants vary among bacterial species. Some possess several DsbA proteins with different substrate specificities that interact with one or more DsbBs, while others have only a single homolog of DsbA and DsbB (Arts et al. 2013; Heras et al. 2010; Sinha et al. 2004). Dsb system diversity also involves the redox partners of periplasmic thiol oxidoreductases. A majority of Dsb oxidases are converted into the oxidized form by proteins homologous to EcDsbB. However, in some bacteria, this function is taken over by DsbI or VKOR proteins. DsbI operates in only a small number of bacteria; it is homologous to the DsbB family and consists of two domains. Its N-terminal domain, consisting of five transmembrane helices, resembles classical DsbB, whereas its periplasmically-located C-terminal adopts a $\beta$-propeller structure (Lasica et al. 2010). VKOR is a bacterial homolog of mammalian vitamin $\mathrm{K}$ epoxide reductase, which is a functional equivalent of EcDsbB (Dutton et al. 2008; Wang et al. 2011). Thiol oxidoreducases playing a role in rearrangements of improper disulfides are kept in reduced forms by at least three structurally similar, but not identical, inner membrane proteins: DsbD, ScsB or CcdA (Cho and Collet 2013; Cho et al. 2012; Katzen et al. 2002; Stirnimann et al. 2006a). It was noted several years ago that $E$. coli cells lacking DsbA and DsbB are still able to generate disulfides. Recently, this function was assigned to a periplasmic protein containing one cysteine residue, PspE, which in cooperation with DsbC, is able to at least partially replace DsbA/DsbB (Chng et al. 2012).

Though most of the thiol oxidoreductases that act as oxidants are monomeric; the list of dimeric thiol oxidoreductases has lengthened (Bocian-Ostrzycka et al. 2015b; Daniels et al. 2010; Kpadeh et al. 2013, 2015). Most of these dimeric thiol oxidoreductases, described so far, act as isomerases and form homodimers. They interact with two redox partners of different structure (DsbD or ScsB) (Cho et al. 2012; Jiao et al. 2013; McCarthy et al. 2000). One of the most complex Dsb systems operates in Legionella pneumophila cells. It consists of two DsbAs (monomeric and dimeric), two DsbBs, and two DsbDs. Interestingly, this microorganism does not possess DsbC and uses dimeric LpDsbA2 not only to form disulfide bonds but also to correct improperly introduced disulfide bonds (Kpadeh et al. 2013, 2015). On the other hand, Helicobacter pylori lacks both classical DsbA/DsbB and DsbC/DsbD homologs. Instead, it uses two untypical Dsb proteins to generate disulfides: HP0231 and HP0377. HP0231 is a dimeric oxidase and HP0377 is an aberrant $\mathrm{CcmG}$ (cytochrome $c$ maturation). In contrast to other CcmGs described so far, HP0377 is bifunctional, acting not only in the reduction of apocytochrome c but, additionally, in disulfide isomerization. HP0377 exists as a mixture of monomeric and dimeric forms (Bocian-Ostrzycka et al. 2015b, 2016; Lester et al. 2015; Roszczenko et al. 2012, 2015).
As mentioned above in Gram-negative bacteria, the process of protein oxidative folding takes place in the periplasm, whereas in Gram-positive bacteria, lacking this compartment, it occurs in the space between the cytoplasmic membrane and the cell wall (Chagnot et al. 2013). Thiol oxidoreductases involved in disulfide generation of some Gram-positive bacteria have been also characterized in regard to their mechanism of action, biochemical features, and structures (Daniels et al. 2010; Heras et al. 2008; Ishihara et al. 1995; Kouwen et al. 2007).

Finally, it should be stressed that even though overwhelming numbers of bacterial species generate disulfide bonds in the periplasm, there are some thermophilic microorganisms belonging to both archeal and bacterial domains that contain many proteins with disulfides in reducing cytosolic compartments. These bacteria, which live under extremely harsh conditions, use this post-translational modification for protein stabilization (Jorda and Yeates 2011; Ladenstein and Ren 2006).

The first part of the paper presents current knowledge of how Dsb systems affect virulence of many pathogenic microorganisms. Next, the review paper presents the strategies used for structural and biochemical characterization of the Dsb proteins that provide insights into details of the mechanisms of their actions. The rapid increase of bacterial antimicrobial resistance in recent years has become a major public health concern in many countries. Many substrates of Dsb system in pathogenic bacteria are extracytoplasmic proteins that are involved in virulence. Thus, the detailed knowledge about Dsb network functioning has enabled initial research to make the Dsb network the target for a new class of antivirulence drugs.

\section{Influence of the Dsb system on virulence - impact on secretion systems and defense against stress conditions}

Pathogenic bacteria produce different virulence factors. A majority of them are extracytoplasmic proteins with varied localization, which ensure adhesion, pathogen survival, and replication inside host cells or modulate the functioning of the host immune system. Thus, bacterial pathogenicity is strictly dependent on correct functioning of the secretion pathways. A classification of secretion systems based mainly on evolutionary and functional relatedness is not completely clear. Gramnegative bacterial secretion systems are classified into six or nine groups designated by Roman or Arabic numerals (Chagnot et al. 2013; Green and Mecsas 2016). In general, proteins are transported by a one- or two-stage process. The first uses complex transporter machinery to deliver effector molecules directly from the bacterial cytoplasm into the cytosol of a wide range of eukaryotic cells. In two-stage transport, proteins are first delivered to the periplasm through the 
bacterial inner membrane, and next they are transported across the outer membrane using various mechanisms.

This chapter will focus on reviewing the role of various secretion pathways in virulence. Emphasis will be given to the impact of the Dsb network on the correct functioning of the process. We present a few examples that document how Dsb protein activity affects both the structures of effector molecules and/or the structures of a wide variety of proteins comprising the macromolecular complex of transport machineries-types of secretion systems occuring among Gramnegative bacteria are shown in Fig. 1.

In the case of T3SS (type three secretion system), T4SS, and also T6SS, effector molecules, mainly proteins, are transported through a secretion system channel that spans three membranes: the inner and outer bacterial cell membranes and the membrane of a eukaryotic cell (Fig. 1a). Molecules that are delivered into host cells are able to convert the physiology of those cells in a way that is advantageous for the pathogen. The transporters of these three systems are complex organelles, sometimes made up of more than 20 proteins (Backert and Meyer 2006; Galan and Wolf-Watz 2006; Moraes et al. 2008). In T3SS, the targets of the Dsb systems are not the effector molecules, which do not transit through the periplasm, but rather, the targets are protein building blocks of the transporter. As a majority of DsbAs show rather broad specificity and react with many substrates, their activity impacts the structures of various proteins involved in the generation of transport machineries. For example, DsbAs are required for the correct folding of Yersenia pestis $\mathrm{YscC}$ and Shigella flexneri Spa32. Both proteins are components of the type 3 secretion apparatus (Jackson and Plano 1999; Watarai et al. 1995). Salmonella enterica possesses two T3SS associated with virulence that are encoded by Salmonella pathogenicity islands 1 and 2 (SPI1 and SPI2). DsbA Salmonella mutant strains show decreased secretion of effectors via the SPI1 T3SS or the SPI2 T3SS. So far, there is no confirmed in vivo target protein for DsbA in the SPI1 T3SS apparatus (Lin et al. 2008). In contrast, SpiA, an outer membrane component of Salmonella's SPI2 T3SS, requires disulfide bond formation to gain correct function (Miki et al. 2004). Additionally, in many pathogenic bacteria the Dsb system plays a role in the regulation of expression of genes involved in T3SS functioning. For example, a Pseudomonas aeruginosa $d s b A$ mutant strain shows reduced T3SS secretion of effector proteins (exoU and exoT). Expression of exoT is regulated by transcriptional activator ExsA, which is not expressed in a $d s b A$ mutant (Ha et al. 2003; Lin et al. 2008).

T4SS secretion machinery is also Dsb-dependent. A Helicobacter pylori strain that does not produce HP0231, the main dimeric thiol oxidoreductase responsible for disulfide bond formation, is avirulent because it does not translocate CagA (cytotoxin associated gene) into gastric epithelial cells (Roszczenko et al. 2012; Zhong et al. 2016). This phenotype potentially results from the wrong conformation of

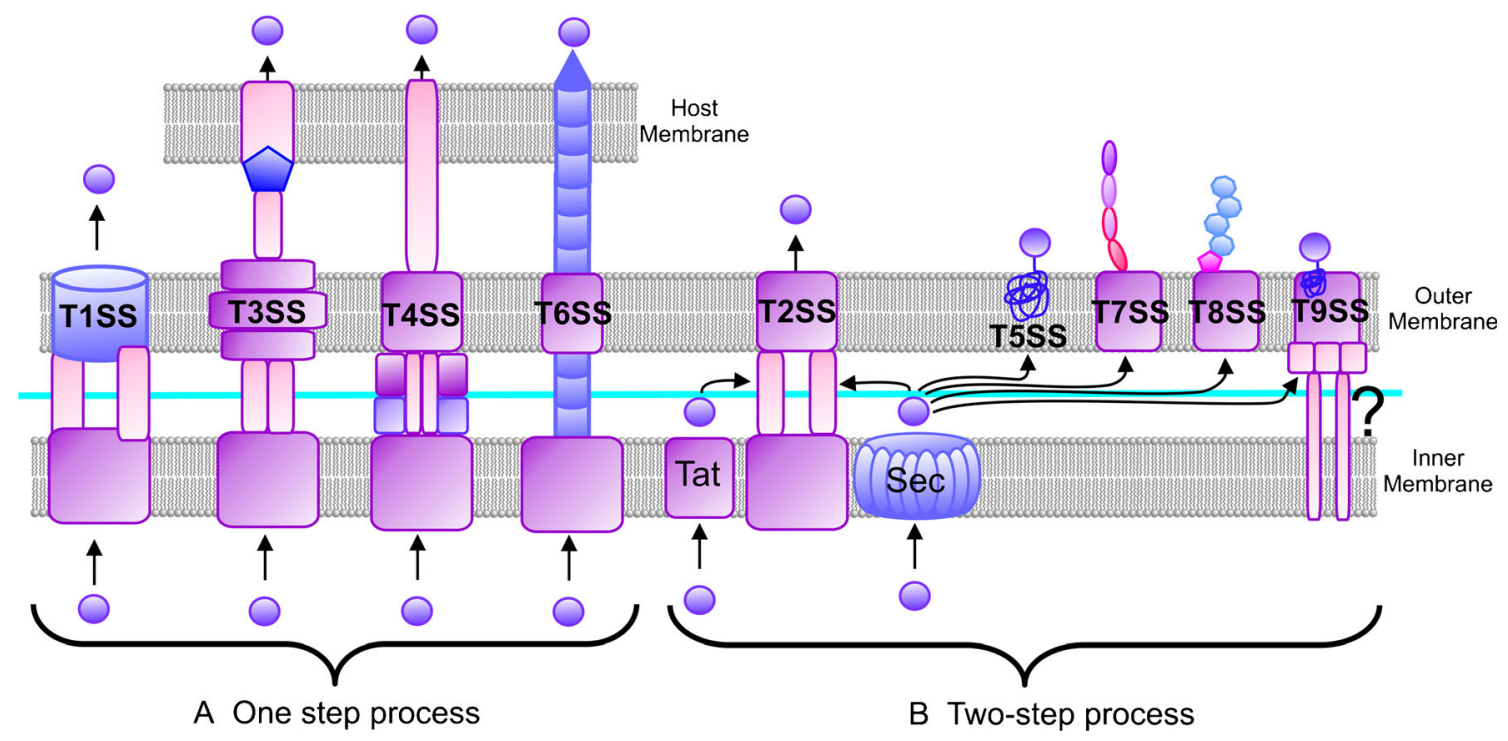

Fig. 1 Secretion systems of Gram-negative bacteria. a. One-step systems (T1SS, T3SS, T4SS, T6SS). In these systems effector molecules, mainly proteins, are delivered directly to the cytosol of a target cell. They are transported through a secretion channel that spans three membranes: the inner and outer bacterial cell membranes and the membrane of a eukaryotic cell. The architecture of the secretion apparatus of each type of system is unique. b. Two-step systems (T2SS - pathway previously named GSP (general secretion pathway), involved also in the formation of Type 4 pili, T5SS - pathway used by autotransporters which do not

need any auxiliary proteins to traverse the outer membrane; T7SS - chaperone-usher pathway involved in pili formation; T8SS - extracellular nucleation-precipitation pathway involved in curli formation; and T9SS - Por (porphirin) secretion system. In these systems proteins cross the inner membrane with the help of either the Sec (secretion) or Tat (twin arginine transportation) pathway and next they are transported across the outer membrane using various mechanisms (for details see Chagnot et al. 2013 and Green and Mecsas 2016) 
CagL, which contains one disulfide bond and acts as a T4SS adhesion protein (Barden et al. 2013; Conradi et al. 2012). Legionella pneumophila DsbA2 (a bifunctional dimeric thiol oxidoreductase) is necessary for proper assembly and function of the T4SS that is essential for invasion and intracellular replication of this pathogen. Several proteins involved in assembly of the secretion apparatus were captured using mutated DsbA2 (P198T) (Jameson-Lee et al. 2011; Kpadeh et al. 2015).

The type 6 secretion system is a one-stage, contactdependent delivery machinery similar to the type 3 and 4 secretion systems. T6SS has been found in more than $25 \%$ of bacterial genomes sequenced so far. In two aspects, T6SS is different from other one-stage secretion pathways. First, type 6 has a different evolutionary origin. Secondly, in contrast to others one-stage secretion systems, it ensures direct contact not only between the pathogen and host cells but sometimes between bacterial cells. Thus, it also plays a role in bacterial antagonism, the competition for a specific ecological niche (Hachani et al. 2016). To the best of our knowledge, there is only one documented example of the influence of the Dsb network on components of the type 6 secretion system. Qin et al. showed that an atypical Dsb of Francisella tulariensis, FipB (FtDsbA), which displays oxidase, isomerase, and chaperone activity, affects the virulence process by influencing proper assembly of the type 6 transport apparatus (Qin et al. 2016).

The ability to adhere to a wide range of surfaces is crucial for many pathogenic bacteria. Specific cell organelles, such as adhesion pili located on the cell surface, are involved in the process. Biogenesis of $E$. coli pili (named chaperone-usher pathway, T7SS) is a well-characterized process that includes transport of all necessary elements via the inner membrane to the periplasm, followed by pilus construction on the cell surface (Lillington et al. 2014). In the periplasm, the proteins necessary for pili assembly, are protected from aggregation and degradation by specific, immunoglobulin-like chaperones: PapD (type Pap pili) or FimC (type 1 pili). The proper assembly of $E$. coli pili is strictly dependent on disulfide generation in pilus subunits or in chaperones (Crespo et al. 2012; Jacob-Dubuisson et al. 1994). Two of the three Neisseria meningitidis DsbAs, lipoproteins that atypically are anchored to the inner membrane are involved in the biogenesis of type IV pili. Furthermore, one of the three DsbAs of Salmonella typhimurium, $\mathrm{SrgF}$, is indispensable for the correct assembly of a plasmid-encoded pili, PefA (Bouwman et al. 2003; Tinsley et al. 2004).

T2SS (Fig. 1b), previously named GSP (general secretion pathway), is a two-stage system that actively participates in transport of broad array of substrates, mainly enzymes (Green and Mecsas 2016). One of them is Vibrio cholerae toxin (CT), the main virulence factor of this pathogen. Inactivation of the gene encoding TcpG (the $V$. cholerae homolog of DsbA) results in avirulence. A strain that is not able to generate disulfides is deficient in colonization because it does not produce toxin co-regulated pili (TCP) and does not secrete cholera toxin. $\mathrm{CT}$ belongs to the family of $\mathrm{AB}_{5}$ toxins, composed of one A subunit (CT-A) with enzymatic activity and five B subunits (CT-B) responsible for toxin transport across the outer membrane and for recognition of specific receptors on the surface of eukaryotic cells. Absence of TcpG results in rapid degradation of the CT-B (Peek and Taylor 1992; Yu and Kaper 1992). Additionally, TcpG has an impact on expression of the main $V$. cholerae transcription activator ToxT, through influencing the structure of two transmembrane regulators, TcpP and ToxR, that contain two cysteine residues in their periplasmic domains (Fengler et al. 2012; Morgan et al. 2015).

The type 5 secretion system, including proteins called autotransporters (AT), is unique in its architecture and mechanism of action. ATs do not need any auxiliary proteins to traverse the outer membrane as their C-terminal translocation domains form specific beta barrel channels in the outer membrane, ensuring transport of the passenger domain to the cell surface or into the environment (Wells et al. 2007). All autotransporters described so far are virulence factors with diverse functions. Most contain a pair of cysteine residues present near the $\mathrm{C}$-terminus of the passenger domain that are targets of the Dsb systems. While lack of Dsb proteins does not strongly interfere with activity of the autotransporters, the Dsb proteins generate disulfide bonds during their periplasmic transit. The process increases stability of the autotransporters and renders them resistant to protease digestion (Bodelon et al. 2009; Brandon and Goldberg 2001; Letley et al. 2006).

Often, but not always, inactivation of genes that encode periplasmic, soluble thiol oxidases results in loss of mobility, and this has a significant impact on virulence. Flagella biogenesis is a complicated, strictly regulated process. In some species, the lack of disulfide bond generation affects the structure of FlgI (P-ring flagellar protein) (Bardwell et al. 1991; Turcot et al. 2001). However, even for strains with homologs of FlgI that do not possess cysteine residues, the knockout of $d s b$ genes sometimes results in loss of motility, indicating that other essential proteins, besides FlgI, for biogenesis of this organelle are also Dsb dependent (Grabowska et al. 2014).

Bacteria often have to survive unfavorable environmental conditions, such as high temperature, high oxygen concentrations, or high concentrations of various metals. Pathogenic bacteria are exposed to harmful reactive oxygen species (ROS), produced not only by their own metabolic processes but also by the host immune system as the bacteria attempt to colonize. Bacteria have therefore evolved many defense mechanisms to circumvent the lethal effect of ROSs. The defense mechanisms fall into two groups: those inactivating ROS and those involved in repairing damaged proteins (Atack and Kelly 2009; Guo and Gross 2014; Wang et al. 2006). Effective defense requires reductive activity, making 
the Dsb proteins essential participants in the protection process. The Dsb proteins involved in electron transport from cytoplasmic thioredoxin to the periplasm (DsbD or ScsB) constitute the hub of the defense, as shown by numerous examples. Bacteria with knockout $d s b$ genes are sensitive to paraquat or hydrogen peroxide (Achard et al. 2009; Lester et al. 2015). Using Caulobacter crescentus as a model organism, Cho et al. surprisingly showed that peroxides are scavenged in the cell envelope by coordinated action of reductive pathway proteins, operating in the oxidative periplasm environment. That coordinated action has three components: membrane ScsB transports electrons from the cytoplasm to a periplasm-located thioredoxin-like TlpA, which subsequently delivers them to peroxidoredoxin PprX. PprX reduces ROS before they can reach cytoplasm (Cho et al. 2012). In E. coli, the interaction between AraF (L-arabinose-binding protein) and $\mathrm{EcDsbC}$ demonstrates another defense mechanism against oxidative stress. EcDsbC protects single cysteine residues against oxidative stress and is involved in reducing disulfide-linked dimers generated by AraF under oxidative stress conditions (Denoncin et al. 2014). In Neisseria gonorrheae, PilB (multifunctional polyprotein), which also depends on DsbD transporting reducing equivalents from the cytoplasm, plays a role in repairing oxidized methionine residues (Brot et al. 2006).

Copper $(\mathrm{Cu})$, a trace metal, is an essential micronutrient for eukaryotic and prokaryotic organisms. However, an excess of copper is cytotoxic under aerobic and anaerobic conditions, and diverse bacterial $\mathrm{Cu}$ detoxification systems contribute to pathogenesis (Djoko et al. 2015). Since copper is an oxidant and catalyzes the generation of non-native disulfides, the defense against copper stress is achieved by the action of thiol oxidoreductases with isomerase activity. (Hiniker et al. 2005). Besides the well-characterized EcDsbC, the periplasm-located, homodimeric thiol oxidoreductase $\mathrm{ScsC}$ of Salmonella typhimurium, which is encoded by the four-gene locus ScsA$D$ (copper sensitivity), is also essential for copper stress protection (Shepherd et al. 2013).

\section{How to distinguish between thiol oxidoreductases functioning as oxidants or reductants}

In vivo, the thiol oxidoreductases involved in disulfide generation are kept in oxidized forms by interaction with homologs of the EcDsbB proteins. On the contrary, Dsbs that function as isomerases are kept in reduced forms. These two forms are undistinguishable using standard SDS-PAGE because they migrate through the polyacrylamide gels at the same speed. Thus, the protein redox states in vivo are examined by modifying their free cysteine residues using AMS (4-acetamido-4'maleimidylstilbene-2,2'-disulfonic acid) or MalPEG (polyethylene glycol (PEG)-conjugated malemide). Both reagents react with free thiol groups to produce a major mobility shift for the modified protein in SDS-PAGE gels (Denoncin et al. 2013; Kpadeh et al. 2013). This method, known as "AMS trapping", allows determination of the redox state of proteins.

Absence of Dsbs involved in oxidative pathways often results in pleiotropic effect because they are proteins of rather low specificity. Thus, generation of isogenic mutants and examination of their phenotypes can be a useful strategy to understand their function. However, because some DsbAs possess high specificity, this strategy sometimes does not permit to identify the effect of gene inactivation by simple checking cell physiological features. It is noticeable especially for bacteria that encode more than one thiol oxidase (Arts et al. 2013; Jameson-Lee et al. 2011). In recent years, the Dsb network of the model microorganism Escherichia coli has been characterized in detail (Denoncin and Collet 2013; Shouldice et al. 2011). To understand how the uncharacterized thiol oxidoreductases function, it is therefore helpful to examine their role in E. coli by complementation analysis. For complementation, the gene of interest is cloned into an appropriate plasmid, usually under an inducible promoter, and introduced into $E$. coli mutants for $d s b A$ or/and $d s b C$. Many phenotypic traits can be checked by standard procedures, including: motility, $\mathrm{Cd}^{2+}$ or $\mathrm{Cu}^{2+}$ resistance, mucoid phenotype and alkaline phosphatase activity (Cho et al. 2014; Dumoulin et al. 2005; Grabowska et al. 2014; Hiniker et al. 2005; Leverrier et al. 2011; Roszczenko et al. 2012, 2015).

The next standard step in analysis of thiol oxidoreductases involves protein purification and determination of the protein's biochemical attributes. The insulin reduction assay is a widely used, standard method to measure oxidoreductase activity. It specifically probes disulfide reductase activity. Insulin contains two intramolecular disulfide bonds that connect the $\mathrm{A}$ and $\mathrm{B}$ chains. The reduction of these disulfide bonds results in precipitation of the $\mathrm{B}$ chain which can be monitored by following absorbance at $650 \mathrm{~nm}$. This strategy reflects protein reducing activity. Thus the oxidant EcDsbA has only about $10 \%$ of the activity of EcDsbC isomerase. Some thiol oxidases of narrow specificity display an even lower activity, as compared to the standard EcDsbA (Arts et al. 2013; Collet et al. 2002; Grabowska et al. 2014; Heras et al. 2008; Holmgren 1979a, b).

The next characteristic feature of thiol oxidoreductases is the redox potential of their CXXC motifs. This is determined from the equilibrium constant with glutathione; the method used depends on the presence or absence of tryptophan residues, using either a fluorometric measurement or evaluating the ratio of reduced and oxidized protein forms by the AMS trapping method (Arts et al. 2013; Lafaye et al. 2009; Roszczenko et al. 2012, 2015). In general terms, the numerous thiol-disulfide oxidoreductases are classified into three types in terms of their redox potentials: low, mid or high potential. Cytoplasmic thioredoxins involved in maintaining protein 
cysteine residues in their reduced form are characterized by low potentials. Disulfide isomerase proteins of mid redox potential play a role in shuffling incorrect disulfides, whereas the high potential thiol oxidoreductases located outside of the cytoplasmic membrane are involved in disulfide generation. An important characteristic of thiol-disulfide oxidoreductases is the lowered $\mathrm{pKa}$ of the reactive cysteine, which determines reactivity in thiol-disulfide exchange reactions. A clear relationship exists between the $\mathrm{pKa}$ values of the active-site cysteine residues and their redox properties: the lower the $\mathrm{pKa}$ value of the $\mathrm{N}$-terminal cysteine residue, the higher (less negative) the reduction (redox) potential (Edeling et al. 2004; Lewin et al. 2008).

To distinguish between oxidizing and isomerase activities, two substrates are employed in most cases: RNaseA from bovine pancreas or hirudin, a small thrombin inhibitor that is secreted by leeches to let them freely suck blood. In their native forms, RNaseA contains four disulfides and hirudin contains three disulfides. The substrates are used in two forms: reduced or scrambled. Thiol oxidoreductases acting as oxidants display activity only with reduced forms of the substrates, whereas isomerases catalyze both disulfide bond isomerization of scrambled proteins and protein oxidation (Bocian-Ostrzycka et al. 2016; Chim et al. 2013; Hiniker et al. 2007; Kurz et al. 2008; Messens et al. 2007; Quan et al. 2007; Ren et al. 2009).

\section{Identifying Dsb protein substrates}

Substrate identification has been crucial in understanding the role of Dsb systems in bacterial pathogenicity. A data based search for proteins with at least one cysteine pair is the initial step to identify Dsb substrates via in silico methods. Results show that cysteine residues are more frequent in cytoplasmic proteins compared to those residing outside the cytoplasm. Additionally, a majority of extracytoplasmic proteins contain an even number of cysteine residues. This trend was named "up and down", which means, for example, that the number of proteins containing four cysteine residues outnumbers those carrying three cysteine residues. Thus, the extracytoplasmic location of proteins with even numbers of cysteine residues is an indication of their Dsb-dependence (Daniels et al. 2010; Dutton et al. 2008). Also, in silico structural modeling supplies informative data about the presence of consecutive or nonconsecutive disulfides. Recently, several algorithmic techniques have been elaborated to determine the presence of disulfides in a protein of interest (Becker et al. 2013; Lin and Tseng 2010; Marquez-Chamorro and Aguilar-Ruiz 2015; Singh 2008).

The results obtained by in silico methodology are confirmed by in vivo or in vitro methods, through global analysis of proteins present in cell-lysates or experiments conducted with purified proteins. The first analysis that identified $E$. coli and $S$. enterica Dsb targets included comparative proteomic experiments (comparison of periplasmic subproteomes derived from wt and $d s b$ mutated strains (Agudo et al. 2004; Hiniker and Bardwell 2004). Originally, it was accepted that proteins containing disulfides are generally periplasmic. However, it has recently been shown that many outermembrane proteins are also Dsb-dependent (Leverrier et al. 2011; Ruiz et al. 2010). Thus, Arts et al. in their comparative proteomics experiments with Pseudomonas aeruginosa wt and PadsbA1-mutated strains used proteins derived from both cellular compartments, the periplasm and the outer-membrane, which identified more than 20 previously unknown PaDsbA1 substrates (Arts et al. 2013).

The mixed complexes between EcDsbA and its substrates are short-lived and are difficult to detect. The CXXC and cisPro loop are highly conserved motifs characteristic for thiol oxidoreductases. It has been shown that mutations in the $E c d s b A$ gene, which alter the conserved cis-proline, facilitate isolation of EcDsbA complexes and allows identification of its substrates. The P151T mutant of EcDsbA slows the second step of oxidative folding, which results in accumulation of EcDsbA complexes with substrates (Kadokura et al. 2004, 2005). Similarly, to trap and purify the substrates linked to a Dsb protein, the C-terminal cysteine of CXXC catalytic site may be replaced by a serine or alanine. These mutated proteins are able to react with their substrates but lack the second cysteine of the catalytic motif required to resolve the mixed disulfide complex. The proteins of cells containing a mutated version of Dsb are then analyzed by SDS-PAGE, with or without reducing agent. Usually, several additional proteins appear after reducing treatment, as compared to the nonreducing condition. They are cut out of the gel and analyzed by mass spectrometry. This method was used to identify EcDsbC substrates by Denoncin et al., EcDsbG targets by Depuydt et al., Plasmodium falciparum thioredoxin substrates by Sturm et al., and Francisella tularensis FtDsbA targets by Ren et al. and Qin et al. (Denoncin et al. 2010, 2014; Depuydt et al. 2009; Qin et al. 2016; Ren et al. 2014; Sturm et al. 2009). The mutated Dsb proteins can also be used to identify their substrates in experiments performed in vitro. In this test, purified Dsb proteins with an appropriate mutation and a HisTag are immobilized on a Ni-NTA agarose column, followed by loading with wild type strain lysate. Dsb complexes are eluted and analyzed by SDS-PAGE under reducing and nonreducing conditions. The Dsb substrates are then identified by mass spectrometry (Ren et al. 2014).

\section{Dsb proteins as targets of new antibacterial drugs}

The discovery of antibiotics and their introduction into common practice was one of the most important medical achievements of the previous century. However, euphoria was brief. Rapid emergence of multiple-drug resistant bacteria has 
increasingly occurred in many parts of the world and constitutes a serious threat to public health and patient safety. According to the European Centre for Disease Prevention and Control (ECDC) (ECDC 2014), WHO (World Health Organization) (WHO 2014), or the CDC (Centers for Disease Control and Prevention) (CDC 2013), each year infections caused by a subset of resistant bacteria are responsible for about 25,000 deaths in Europe and more than 20,000 in USA. The problem of resistance involves both Gram-positive and Gramnegative pathogens that cause infections in the hospital and in the community. Success at fighting infectious disease will depend upon development of new, effective, and safe antimicrobial compounds. More than 20 novel classes of antibiotics were introduced into the market between 1930 and 1962. Since then, only two new classes of antibiotics have been introduced (Bassetti et al. 2013; Boucher et al. 2009; Ventola 2015a, b). In recent years, scientists have implemented new strategies to grow microbes found in soil, and these approaches resulted in identification of two new antibacterial substances: teixobacin and lungdunin (Ling et al. 2015; Zipperer et al. 2016). One widely explored approach to generate new classes of antibacterial drugs focuses on targeting virulence rather than the viability of bacteria. Numerous proteins or processes have been selected as targets of therapeutic value. In general, the new inhibitors can be classified into two categories: those blocking a single virulence factor, such as adhesin or toxin, and those with a global activity to block major bacterial processes such as quorum sensing, the two-components system, secretion systems or post-translational protein modification (Brackman and Coenye 2015a, b; Duncan et al. 2012; Felise et al. 2008; Kalia 2013; Krachler and Orth 2013).

Proteins of the Dsb system, which play a key role in the virulence of many pathogenic microorganisms, represent possible new drug targets. Inhibition of their interactions with substrates or their redox partners could constitute a means of blocking the formation of virulence factors. The location of the Dsb proteins (in the bacterial periplasm) renders them easily accessible to potential small-molecule inhibitors. Potential sites of action of Dsb system inhibitors are shown in Fig. 2. Furthermore, use of a Dsb-protein inhibitor should not create selective pressure for developing resistance. However, it should be noted than some Dsbs have homologous proteins in eukaryotes, so inhibitors need to be vetted in detail for any detrimental effects in vertebrates.

While enormous progress has been made in understanding the mechanisms of Dsb proteins, their interdependence and the diversity of Dsb networks among bacteria, as well as the influence of Dsbs on virulence, structural biology is a key factor for initiating research on therapeutic application of Dsb inhibitors. Most interest has been directed towards solving the structures of homologs of EcDsbA proteins because they are responsible for disulfide generation. The number of crystallographic studies of DsbA homologs has increased at lightning pace, with 76 structures of DsbA proteins now deposited in the Protein Data Bank (PDB). Although all monomeric DsbAs share essential structural features (presence of the thioredoxin fold, with CXXC and cis-pro motifs), they differ substantially in charge distribution on the surface and structural attributes in the region surrounding active site. These subtle differences find reflection in dissimilarities in their biochemical properties and specificity for various substrates. Comparison of the structures and biochemical attributes of 13 DsbA homologs grouped them into two classes that subsequently, based on surface features, were divided into four subclasses (McMahon et al. 2014). Solving the structure of the EcDsbA/EcDsbB complex indicated which fragments of both proteins played a role in their mutual interaction, and this was a starting point to search for inhibitors of the process (see below) (Inaba et al. 2006; Zhou et al. 2008). Structures of homodimeric Dsbs (DsbC and DsbG), have been also solved, and this facilitates understanding of their functioning (Heras et al. 2004; McCarthy et al. 2000). Additionally, knowledge about the complicated process of transporting reducing power from the cytoplasm to the periplasm has recently deepened (Stirnimann et al. 2006a, b; Williamson et al. 2015). Although current research on inhibitors of the Dsb system mainly concentrates on disulfide generation, it is probable that blocking enzymes involved in rearranging improper disulfide bonds might also provide positive results.

The identification of small molecules working as inhibitors of virulence is a lengthy and expensive process. With the growing availability of drug libraries and automatic robotic systems, the first step to search for Dsb inhibitors involves high throughput screening (HTS). This approach rapidly tests large numbers of compounds. HTS usually requires a specific strategy to detect inhibitor activity on analyzed proteins, such as construction of fusion proteins for in vitro or in vivo tests or specific techniques to catch direct interaction of an inhibitor with purified protein/s. The complementary approach to look for Dsb inhibitors makes use of in silico analysis combined with the solved structure of a protein. They are referred as SBVS (structure-based virtual screening) and SBDD (structure-based drug design), or RTDD (rational target-based drug design). Further in silico studies aimed at structural analysis of potential drugs enables introduction of chemical modifications that may lead to more effective compounds.

So far, potential Dsb system inhibitors have been identified by both HTS and SBVS techniques. Landeta et al. searched for compounds interacting with EcDsbB by in vivo HTS. For this approach, the authors applied a specific agar, multi-well test in combination with $E$. coli expressing a genetically modified beta galactosidase MalF- $\beta$-Gal fusion. The hybrid protein MalF- $\beta$-Gal102, containing $\beta-$ Gal fused to the large periplasmic domain of MalF, does not show $\beta$-Gal activity in weight cells due to the introduction of disulfide bonds, but it is active in cells that are defective in disulfide bond formation 
Fig. 2 Potential sites of action of Dsb system inhibitors. a. Blocking interaction of EcDsbB with ubiquinone, b. blocking interaction of EcDsbA with its substrates, and $c$ blocking EcDsbA reoxidation by EcDsbB

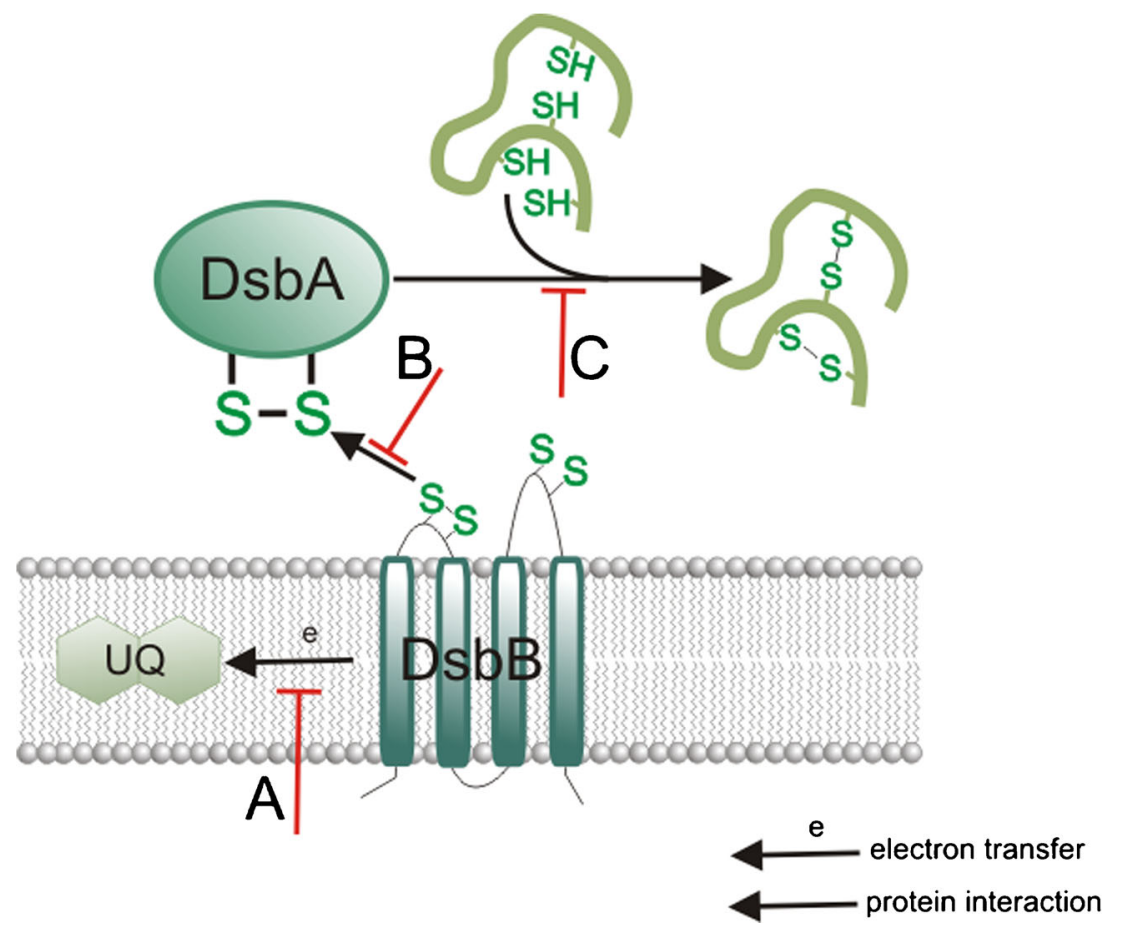

(Beckwith 2013). Among more than 50,000 screened compounds derived from two collections, six that inhibited EcDsbB and possess similar piridazinone ring structures were selected. Further in silico analysis led to identification of even more effective molecules with a similar structure. These inhibitors interfere with the interaction of EcDsbB C44 with ubiquinone. Although the researchers did not find any specific VKOR inhibitors, they documented that their strategy might be useful to search for anti-Mycobacterium tuberculosis drugs (Landeta et al. 2015). Adams et al. looked for molecules able to inhibit EcDsbA. They screened 1132 compounds by in vitro HTS methodology employing STD-NMR spectra and identified several potential inhibitors. The compound with greatest potency was further tested using a peptide oxidation assay and a bacterial motility test (Kurth et al. 2013). Based on the structure of this molecule, the authors inferred that it interacts with a hydrophobic groove close to the active site of EcDsbA (Adams et al. 2015). Given that homologs of DsbA share structural similarities with eukaryotic proteins of the thioredoxin family, emphasis was put on identifying inhibitors of the DsbA redox partner, DsbB. This is not easy because DsbB is an inner membrane protein with four transmembrane domains, which makes purification of fully active protein a real challenge. Fruth et al. developed a method for EcDsbB solubilization and used immobilized DsbB for a screening test. Among 1071 components in a drug-fragment library, they selected eight that interacted with EcDsbB, as validated by biochemical and biophysical methods (Fruh et al. 2010). Although this work may be a starting point to identify inhibitors of membrane proteins, work by Halili et al. showed that the data should be treated with caution, and that variation in the experimental conditions may result in different results (Halili et al. 2015). They selected one of the inhibitors identified by Furth et al. (compound number 1) and verified its activity against $\mathrm{DsbB}$ in a peptide oxidase assay. The rationale behind their choice concerns the compound's function: it competes with ubiquinone for the EcDsbB binding site. Interestingly, they found that compound number 1 is a poor inhibitor of the process of electron transport. Using SAR strategy, they generated a library of several analogs of compound number 1 and examined their ability to block the oxidative Dsb pathway using various biochemical and biophysical assays. Some analogs displayed 1000 times higher activity than the starting compound. Finally, they selected one of the molecules with the greatest potency and showed that it reacts with both DsbA and DsbB (Halili et al. 2015).

Another approach took advantage of the solved structure of the covalent EcDsbA $\backslash$ EcDsbB complex. The work of Inaba et al. documented that a short seven-residue peptide, part of the second periplasmic loop of EcDsbB, ensures the EcDsbA/ EcDsbB interaction. Further inspection of the complex structure showed that this fragment containing EcDsbB Cys 104 was found inside the long cavity of EcDsbA. The EcDsbB Cys 104 residue creates a disulfide bond with Cys30 of EcDsbA, and this is an indispensable element of the EcDsbA reoxidation process (Inaba et al. 2006). Based on these data, Duprez et al. synthesized several EcDsbBderived peptides to find ones that strongly compete with native EcDsbB for EcDsbA binding. The authors confirmed binding of the slightly modified native peptide with EcDsbA 
and subsequently examined details of the process. They determined the structure of EcDsbA complexed with the peptide, and they used biochemical analysis of modified versions of the peptide to show the crucial role of the cysteine residue and document the influence of peptide length on efficiency of the process (Duprez et al. 2015b). Given possible anti-virulence application of this work, the same research group employed SBVS to design a more efficacious inhibitor. The solved structure of the non-covalent Pm (Proteus mirabilis) DsbA/ heptapeptide complex was the starting point for virtual screening of a peptidomimetic library (Kurth et al. 2014). Subsequently, ten peptidomimetic compounds were examined for their binding to the hydrophobic groove of EcDsbA by biophysical and biochemical methods, but none of them displayed stronger binding than the short peptide derived from native EcDsbB (Duprez et al. 2015a).

\section{Conclusions}

In recent years, Dsb systems of many bacterial species have been characterized. Understanding the biochemical activities of these proteins, in combination with resolution of their structures and elucidation of their influence on pathogenicity, should help combat infectious disease.

Acknowledgements We thank Dr. J. Hansen for his critical reading of the manuscript.

\section{Compliance with ethical standards}

Ethical approval This article does not contain any studies with human participants or animals performed by any of the authors.

Conflict of interest All authors declare that they have no conflict of interest.

Consent of publication All authors approved the final version of the manuscript.

Funding This study was funded by the National Science Centre, Poland (grant No 2015/17/B/NZ1/00230).

Open Access This article is distributed under the terms of the Creative Commons Attribution 4.0 International License (http:// creativecommons.org/licenses/by/4.0/), which permits unrestricted use, distribution, and reproduction in any medium, provided you give appropriate credit to the original author(s) and the source, provide a link to the Creative Commons license, and indicate if changes were made.

\section{References}

Achard ME, Hamilton AJ, Dankowski T, Heras B, Schembri MS, Edwards JL, Jennings MP, McEwan AG (2009) A periplasmic thioredoxin-like protein plays a role in defense against oxidative stress in Neisseria gonorrhoeae. Infect Immun 77:4934-4939. doi: 10.1128/IAI.00714-09

Adams LA, Sharma P, Mohanty B, Ilyichova OV, Mulcair MD, Williams ML, Gleeson EC, Totsika M, Doak BC, Caria S, Rimmer K, Horne J, Shouldice SR, Vazirani M, Headey SJ, Plumb BR, Martin JL, Heras B, Simpson JS, Scanlon MJ (2015) Application of fragment-based screening to the design of inhibitors of Escherichia coli DsbA. Angew Chem Int Ed Engl 54:2179-2184. doi:10.1002/anie.201410341

Agudo D, Mendoza MT, Castanares C, Nombela C, Rotger R (2004) A proteomic approach to study Salmonella typhi periplasmic proteins altered by a lack of the DsbA thiol: disulfide isomerase. Proteomics 4:355-363. doi:10.1002/pmic.200300554

Arts IS, Ball G, Leverrier P, Garvis S, Nicolaes V, Vertommen D, Ize B, Tamu Dufe V, Messens J, Voulhoux R, Collet JF (2013) Dissecting the machinery that introduces disulfide bonds in Pseudomonas aeruginosa. MBio 4:e00912-e00913. doi:10.1128/mBio.00912-13

Atack JM, Kelly DJ (2009) Oxidative stress in Campylobacter jejuni: responses, resistance and regulation. Future Microbiol 4:677-690. doi: $10.2217 / \mathrm{fmb} .09 .44$

Backert S, Meyer TF (2006) Type IV secretion systems and their effectors in bacterial pathogenesis. Curr Opin Microbiol 9:207-217. doi:10. 1016/j.mib.2006.02.008

Barden S, Lange S, Tegtmeyer N, Conradi J, Sewald N, Backert S, Niemann HH (2013) A helical RGD motif promoting cell adhesion: crystal structures of the Helicobacter pylori type IV secretion system pilus protein CagL. Structure 21:1931-1941. doi:10.1016/j.str.2013. 08.018

Bardwell JC, McGovern K, Beckwith J (1991) Identification of a protein required for disulfide bond formation in vivo. Cell 67:581-589. doi: 10.1016/0092-8674(91)90532-4

Bassetti M, Merelli M, Temperoni C, Astilean A (2013) New antibiotics for bad bugs: where are we? Ann Clin Microbiol Antimicrob 12:22. doi:10.1186/1476-0711-12-22

Becker J, Maes F, Wehenkel L (2013) On the relevance of sophisticated structural annotations for disulfide connectivity pattern prediction. PLoS One 8:e56621. doi:10.1371/journal.pone.0056621

Beckwith J (2013) Fifty years fused to lac. Annu Rev Microbiol 67:1-19. doi:10.1146/annurev-micro-092412-155732

Berkmen M (2012) Production of disulfide-bonded proteins in Escherichia coli. Protein Expr Purif 82:240-251. doi:10.1016/j. pep.2011.10.009

Bocian-Ostrzycka KM, Grzeszczuk MJ, Dziewit L, Jagusztyn-Krynicka EK (2015a) Diversity of the Epsilonproteobacteria Dsb (disulfide bond) systems. Front Microbiol 6:570. doi:10.3389/fmicb.2015. 00570

Bocian-Ostrzycka KM, Lasica AM, Dunin-Horkawicz S, Grzeszczuk MJ, Drabik K, Dobosz AM, Godlewska R, Nowak E, Collet JF, Jagusztyn-Krynicka EK (2015b) Functional and evolutionary analyses of Helicobacter pylori HP0231 (DsbK) protein with strong oxidative and chaperone activity characterized by a highly diverged dimerization domain. Front Microbiol 6:1065. doi:10.3389/fmicb. 2015.01065

Bocian-Ostrzycka KM, Grzeszczuk MJ, Banas AM, Jastrzab K, Pisarczyk K, Kolarzyk A, Lasica AM, Collet JF, JagusztynKrynicka EK (2016) Engineering of Helicobacter pylori Dimeric Oxidoreductase DsbK (HP0231). Front Microbiol 7:1158. doi:10. 3389/fmicb.2016.01158

Bodelon G, Marin E, Fernandez LA (2009) Role of periplasmic chaperones and BamA (YaeT/Omp85) in folding and secretion of intimin from enteropathogenic Escherichia coli strains. J Bacteriol 191: 5169-5179. doi:10.1128/JB.00458-09

Boucher HW, Talbot GH, Bradley JS, Edwards JE, Gilbert D, Rice LB, Scheld M, Spellberg B, Bartlett J (2009) Bad bugs, no drugs: no ESKAPE! An update from the Infectious Diseases Society of America. Clin Infect Dis 48:1-12. doi:10.1086/595011 
Bouwman CW, Kohli M, Killoran A, Touchie GA, Kadner RJ, Martin NL (2003) Characterization of SrgA, a Salmonella enterica serovar Typhimurium virulence plasmid-encoded paralogue of the disulfide oxidoreductase DsbA, essential for biogenesis of plasmid-encoded fimbriae. J Bacteriol 185:991-1000. doi:10.1128/JB.185.3.9911000.2003

Brackman G, Coenye T (2015a) Inhibition of quorum sensing in Staphylococcus spp. Curr Pharm Des 21:2101-2108

Brackman G, Coenye T (2015b) Quorum sensing inhibitors as antibiofilm agents. Curr Pharm Des 21:5-11

Brandon LD, Goldberg MB (2001) Periplasmic transit and disulfide bond formation of the autotransported Shigella protein IcsA. J Bacteriol 183:951-958. doi:10.1128/JB.183.3.951-958.2001

Brot N, Collet JF, Johnson LC, Jonsson TJ, Weissbach H, Lowther WT (2006) The thioredoxin domain of Neisseria gonorrhoeae PilB can use electrons from $\mathrm{DsbD}$ to reduce downstream methionine sulfoxide reductases. J Biol Chem 281:32668-32675. doi:10.1074/jbc. M604971200

CDC (2013) Antibiotic resistance threats in the United States. CDC, Atlanta

Chagnot C, Zorgani MA, Astruc T, Desvaux M (2013) Proteinaceous determinants of surface colonization in bacteria: bacterial adhesion and biofilm formation from a protein secretion perspective. Front Microbiol 4:303. doi:10.3389/fmicb.2013.00303

Chim N, Harmston CA, Guzman DJ, Goulding CW (2013) Structural and biochemical characterization of the essential DsbA-like disulfide bond forming protein from Mycobacterium tuberculosis. BMC Struct Biol 13:23. doi:10.1186/1472-6807-13-23

Chng SS, Dutton RJ, Denoncin K, Vertommen D, Collet JF, Kadokura H, Beckwith J (2012) Overexpression of the rhodanese PspE, a single cysteine-containing protein, restores disulphide bond formation to an Escherichia coli strain lacking DsbA. Mol Microbiol 85:9961006. doi:10.1111/j.1365-2958.2012.08157.x

Cho SH, Collet JF (2013) Many roles of the bacterial envelope reducing pathways. Antioxid Redox Signal 18:1690-1698. doi:10.1089/ars. 2012.4962

Cho SH, Parsonage D, Thurston C, Dutton RJ, Poole LB, Collet JF, Beckwith J (2012) A new family of membrane electron transporters and its substrates, including a new cell envelope peroxiredoxin, reveal a broadened reductive capacity of the oxidative bacterial cell envelope. mBio 3. doi:10.1128/mBio.00291-11

Cho SH, Szewczyk J, Pesavento C, Zietek M, Banzhaf M, Roszczenko P, Asmar A, Laloux G, Hov AK, Leverrier P, Van der Henst C, Vertommen D, Typas A, Collet JF (2014) Detecting envelope stress by monitoring beta-barrel assembly. Cell 159:1652-1664. doi:10. 1016/j.cell.2014.11.045

Collet JF, Riemer J, Bader MW, Bardwell JC (2002) Reconstitution of a disulfide isomerization system. J Biol Chem 277:26886-26892. doi: 10.1074/jbc.M203028200

Conradi J, Tegtmeyer N, Wozna M, Wissbrock M, Michalek C, Gagell C, Cover TL, Frank R, Sewald N, Backert S (2012) An RGD helper sequence in CagL of Helicobacter pylori assists in interactions with integrins and injection of CagA. Front Cell Infect Microbiol 2:70. doi: $10.3389 /$ fcimb. 2012.00070

Crespo MD, Puorger C, Scharer MA, Eidam O, Grutter MG, Capitani G, Glockshuber R (2012) Quality control of disulfide bond formation in pilus subunits by the chaperone FimC. Nat Chem Biol 8:707-713. doi:10.1038/nchembio.1019

Daniels R, Mellroth P, Bernsel A, Neiers F, Normark S, von Heijne G, Henriques-Normark B (2010) Disulfide bond formation and cysteine exclusion in gram-positive bacteria. J Biol Chem 285:33003309. doi:10.1074/jbc.M109.081398

Denoncin K, Collet JF (2013) Disulfide bond formation in the bacterial periplasm: major achievements and challenges ahead. Antioxid Redox Signal 19:63-71. doi:10.1089/ars.2012.4864
Denoncin K, Vertommen D, Paek E, Collet JF (2010) The proteindisulfide isomerase DsbC cooperates with SurA and DsbA in the assembly of the essential beta-barrel protein LptD. J Biol Chem 285: 29425-29433. doi:10.1074/jbc.M110.119321

Denoncin K, Nicolaes V, Cho SH, Leverrier P, Collet JF (2013) Protein disulfide bond formation in the periplasm: determination of the in vivo redox state of cysteine residues. Methods Mol Biol 966: 325-336. doi:10.1007/978-1-62703-245-2 20

Denoncin K, Vertommen D, Arts IS, Goemans CV, Rahuel-Clermont S, Messens J, Collet JF (2014) A new role for Escherichia coli DsbC protein in protection against oxidative stress. J Biol Chem 289: 12356-12364. doi:10.1074/jbc.M114.554055

Depuydt M, Leonard SE, Vertommen D, Denoncin K, Morsomme P, Wahni K, Messens J, Carroll KS, Collet JF (2009) A periplasmic reducing system protects single cysteine residues from oxidation. Science 326:1109-1111. doi:10.1126/science.1179557

Djoko KY, Ong CL, Walker MJ, McEwan AG (2015) The role of copper and zinc toxicity in innate immune defense against bacterial pathogens. J Biol Chem 290:18954-18961. doi:10.1074/jbc.R115. 647099

Dumoulin A, Grauschopf U, Bischoff M, Thony-Meyer L, Berger-Bachi B (2005) Staphylococcus aureus DsbA is a membrane-bound lipoprotein with thiol-disulfide oxidoreductase activity. Arch Microbiol 184:117-128. doi:10.1007/s00203-005-0024-1

Duncan MC, Linington RG, Auerbuch V (2012) Chemical inhibitors of the type three secretion system: disarming bacterial pathogens. Antimicrob Agents Chemother 56:5433-5441. doi:10.1128/AAC. 00975-12

Duprez W, Bachu P, Stoermer MJ, Tay S, McMahon RM, Fairlie DP, Martin JL (2015a) Virtual screening of peptide and peptidomimetic fragments targeted to inhibit bacterial dithiol oxidase DsbA. PLoS One 10:e0133805. doi:10.1371/journal.pone.0133805

Duprez W, Premkumar L, Halili MA, Lindahl F, Reid RC, Fairlie DP, Martin JL (2015b) Peptide inhibitors of the Escherichia coli DsbA oxidative machinery essential for bacterial virulence. J Med Chem 58:577-587. doi: $10.1021 / \mathrm{jm} 500955 \mathrm{~s}$

Dutton RJ, Boyd D, Berkmen M, Beckwith J (2008) Bacterial species exhibit diversity in their mechanisms and capacity for protein disulfide bond formation. Proc Natl Acad Sci U S A 105:11933-11938. doi:10.1073/pnas.0804621105

ECDC (2014) Antimicrobial resistance surveillance in Europe

Edeling MA, Ahuja U, Heras B, Thony-Meyer L, Martin JL (2004) The acidic nature of the $\mathrm{CcmG}$ redox-active center is important for cytochrome c maturation in Escherichia coli. J Bacteriol 186:4030 4033. doi:10.1128/JB.186.12.4030-4033.2004

Felise HB, Nguyen HV, Pfuetzner RA, Barry KC, Jackson SR, Blanc MP, Bronstein PA, Kline T, Miller SI (2008) An inhibitor of gramnegative bacterial virulence protein secretion. Cell Host Microbe 4:325-336. doi:10.1016/j.chom.2008.08.001

Fengler VH, Boritsch EC, Tutz S, Seper A, Ebner H, Roier S, Schild S, Reidl J (2012) Disulfide bond formation and ToxR activity in Vibrio cholerae. PLoS One 7:e47756. doi:10.1371/journal.pone.0047756

Fruh V, Zhou Y, Chen D, Loch C, Ab E, Grinkova YN, Verheij H, Sligar SG, Bushweller JH, Siegal G (2010) Application of fragment-based drug discovery to membrane proteins: identification of ligands of the integral membrane enzyme DsbB. Chem Biol 17:881-891. doi:10. 1016/j.chembiol.2010.06.011

Galan JE, Wolf-Watz H (2006) Protein delivery into eukaryotic cells by type III secretion machines. Nature 444:567-573. doi:10.1038/ nature 05272

Grabowska AD, Wywial E, Dunin-Horkawicz S, Lasica AM, Wosten MM, Nagy-Staron A, Godlewska R, Bocian-Ostrzycka K, Pienkowska K, Laniewski P, Bujnicki JM, van Putten JP, Jagusztyn-Krynicka EK (2014) Functional and bioinformatics analysis of two Campylobacter jejuni homologs of the thiol-disulfide 
oxidoreductase, DsbA. PLoS One 9:e106247. doi:10.1371/journal. pone. 0106247

Green ER, Mecsas J (2016) Bacterial secretion systems: an overview. Microbiol Spectr 4. doi:10.1128/microbiolspec.VMBF-0012-2015

Grimshaw JP, Stirnimann CU, Brozzo MS, Malojcic G, Grutter MG, Capitani G, Glockshuber R (2008) DsbL and DsbI form a specific dithiol oxidase system for periplasmic arylsulfate sulfotransferase in uropathogenic Escherichia coli. J Mol Biol 380:667-680. doi:10. 1016/j.jmb.2008.05.031

Guo MS, Gross CA (2014) Stress-induced remodeling of the bacterial proteome. Curr Biol 24:R424-R434. doi:10.1016/j.cub.2014.03. 023

Ha UH, Wang Y, Jin S (2003) DsbA of Pseudomonas aeruginosa is essential for multiple virulence factors. Infect Immun 71:1590-1595

Hachani A, Wood TE, Filloux A (2016) Type VI secretion and anti-host effectors. Curr Opin Microbiol 29:81-93. doi:10.1016/j.mib.2015. 11.006

Halili MA, Bachu P, Lindahl F, Bechara C, Mohanty B, Reid RC, Scanlon MJ, Robinson CV, Fairlie DP, Martin JL (2015) Small molecule inhibitors of disulfide bond formation by the bacterial DsbA-DsbB dual enzyme system. ACS Chem Biol. doi:10.1021/cb500988r

Heras B, Edeling MA, Schirra HJ, Raina S, Martin JL (2004) Crystal structures of the DsbG disulfide isomerase reveal an unstable disulfide. Proc Natl Acad Sci U S A 101:8876-8881. doi:10.1073/pnas. 0402769101

Heras B, Kurz M, Jarrott R, Shouldice SR, Frei P, Robin G, Cemazar M, Thony-Meyer L, Glockshuber R, Martin JL (2008) Staphylococcus aureus DsbA does not have a destabilizing disulfide. A new paradigm for bacterial oxidative folding. J Biol Chem 283:4261-4271. doi:10.1074/jbc.M707838200

Heras B, Shouldice SR, Totsika M, Scanlon MJ, Schembri MA, Martin JL (2009) DSB proteins and bacterial pathogenicity. Nat Rev Microbiol 7:215-225. doi:10.1038/nrmicro2087

Heras B, Totsika M, Jarrott R, Shouldice SR, Guncar G, Achard ME, Wells TJ, Argente MP, McEwan AG, Schembri MA (2010) Structural and functional characterization of three DsbA paralogues from Salmonella enterica serovar typhimurium. J Biol Chem 285: 18423-18432. doi:10.1074/jbc.M110.101360

Hiniker A, Bardwell JC (2004) In vivo substrate specificity of periplasmic disulfide oxidoreductases. J Biol Chem 279:12967-12973. doi:10. 1074/jbc.M311391200

Hiniker A, Collet JF, Bardwell JC (2005) Copper stress causes an in vivo requirement for the Escherichia coli disulfide isomerase DsbC. J Biol Chem 280:33785-33791. doi:10.1074/jbc.M505742200

Hiniker A, Ren G, Heras B, Zheng Y, Laurinec S, Jobson RW, Stuckey JA, Martin JL, Bardwell JC (2007) Laboratory evolution of one disulfide isomerase to resemble another. Proc Natl Acad Sci U S A 104:11670-11675. doi:10.1073/pnas.0704692104

Holmgren A (1979a) Reduction of disulfides by thioredoxin. Exceptional reactivity of insulin and suggested functions of thioredoxin in mechanism of hormone action. J Biol Chem 254:9113-9119

Holmgren A (1979b) Thioredoxin catalyzes the reduction of insulin disulfides by dithiothreitol and dihydrolipoamide. J Biol Chem 254:9627-9632

Inaba K, Murakami S, Suzuki M, Nakagawa A, Yamashita E, Okada K, Ito K (2006) Crystal structure of the DsbB-DsbA complex reveals a mechanism of disulfide bond generation. Cell 127:789-801. doi:10. 1016/j.cell.2006.10.034

Ishihara T, Tomita H, Hasegawa Y, Tsukagoshi N, Yamagata H, Udaka S (1995) Cloning and characterization of the gene for a protein thioldisulfide oxidoreductase in Bacillus brevis. J Bacteriol 177:745749. doi:10.1128/jb.177.3.745-749.1995

Jackson MW, Plano GV (1999) DsbA is required for stable expression of outer membrane protein YscC and for efficient Yop secretion in Yersinia pestis. J Bacteriol 181:5126-5130
Jacob-Dubuisson F, Pinkner J, Xu Z, Striker R, Padmanhaban A, Hultgren SJ (1994) PapD chaperone function in pilus biogenesis depends on oxidant and chaperone-like activities of DsbA. Proc Natl Acad Sci U S A 91:11552-11556

Jameson-Lee M, Garduno RA, Hoffman PS (2011) DsbA2 (27 kDa Com1-like protein) of Legionella pneumophila catalyses extracytoplasmic disulphide-bond formation in proteins including the dot/Icm type IV secretion system. Mol Microbiol 80:835-852. doi:10.1111/j.1365-2958.2011.07615.x

Jiao L, Kim JS, Song WS, Yoon BY, Lee K, Ha NC (2013) Crystal structure of the periplasmic disulfide-bond isomerase DsbC from Salmonella enterica serovar Typhimurium and the mechanistic implications. J Struct Biol 183:1-10. doi:10.1016/j.jsb.2013.05.013

Jorda J, Yeates TO (2011) Widespread disulfide bonding in proteins from thermophilic archaea. Archaea 2011:409156. doi:10.1155/2011/ 409156

Kadokura H, Beckwith J (2010) Mechanisms of oxidative protein folding in the bacterial cell envelope. Antioxid Redox Signal 13:12311246. doi:10.1089/ars.2010.3187

Kadokura H, Tian H, Zander T, Bardwell JC, Beckwith J (2004) Snapshots of DsbA in action: detection of proteins in the process of oxidative folding. Science 303:534-537. doi:10.1126/science. 1091724

Kadokura H, Nichols L 2nd, Beckwith J (2005) Mutational alterations of the key cis proline residue that cause accumulation of enzymatic reaction intermediates of DsbA, a member of the thioredoxin superfamily. J Bacteriol 187:1519-1522. doi:10.1128/JB.187.4.15191522.2005

Kalia VC (2013) Quorum sensing inhibitors: an overview. Biotechnol Adv 31:224-245. doi:10.1016/j.biotechadv.2012.10.004

Katzen F, Deshmukh M, Daldal F, Beckwith J (2002) Evolutionary domain fusion expanded the substrate specificity of the transmembrane electron transporter DsbD. EMBO J 21:3960-3969. doi:10.1093/ emboj/cdf405

Kouwen TR, van der Goot A, Dorenbos R, Winter T, Antelmann H, Plaisier MC, Quax WJ, van Dijl JM, Dubois JY (2007) Thioldisulphide oxidoreductase modules in the low-GC Gram-positive bacteria. Mol Microbiol 64:984-999. doi:10.1111/j.1365-2958. 2007.05707.x

Kpadeh ZZ, Jameson-Lee M, Yeh AJ, Chertihin O, Shumilin IA, Dey R, Day SR, Hoffman PS (2013) Disulfide bond oxidoreductase DsbA2 of Legionella pneumophila exhibits protein disulfide isomerase activity. J Bacteriol 195:1825-1833. doi:10.1128/JB.01949-12

Kpadeh ZZ, Day SR, Mills BW, Hoffman PS (2015) Legionella pneumophila utilizes a single-player disulfide-bond oxidoreductase system to manage disulfide bond formation and isomerization. Mol Microbiol 95:1054-1069. doi: 10.1111/mmi.12914

Krachler AM, Orth K (2013) Targeting the bacteria-host interface: strategies in anti-adhesion therapy. Virulence 4:284-294. doi:10.4161/ viru. 24606

Kurth F, Rimmer K, Premkumar L, Mohanty B, Duprez W, Halili MA, Shouldice SR, Heras B, Fairlie DP, Scanlon MJ, Martin JL (2013) Comparative sequence, structure and redox analyses of Klebsiella pneumoniae DsbA show that anti-virulence target DsbA enzymes fall into distinct classes. PLoS One 8:e80210. doi:10.1371/journal. pone. 0080210

Kurth F, Duprez W, Premkumar L, Schembri MA, Fairlie DP, Martin JL (2014) Crystal structure of the dithiol oxidase DsbA enzyme from Proteus mirabilis bound non-covalently to an active site peptide ligand. J Biol Chem 289:19810-19822. doi: 10.1074/jbc.M114. 552380

Kurz M, Iturbe-Ormaetxe I, Jarrott R, Cowieson N, Robin G, Jones A, King GJ, Frei P, Glockshuber R, O'Neill SL, Heras B, Martin JL (2008) Cloning, expression, purification and characterization of a DsbA-like protein from Wolbachia pipientis. Protein Expr Purif 59:266-273. doi:10.1016/j.pep.2008.02.008 
Ladenstein R, Ren B (2006) Protein disulfides and protein disulfide oxidoreductases in hyperthermophiles. FEBS J 273:4170-4185. doi: 10.1111/j.1742-4658.2006.05421.x

Lafaye C, Iwema T, Carpentier P, Jullian-Binard C, Kroll JS, Collet JF, Serre L (2009) Biochemical and structural study of the homologues of the thiol-disulfide oxidoreductase DsbA in Neisseria meningitidis. J Mol Biol 392:952-966. doi:10.1016/j.jmb.2009.07. 056

Landeta C, Blazyk JL, Hatahet F, Meehan BM, Eser M, Myrick A, Bronstain L, Minami S, Arnold H, Ke N, Rubin EJ, Furie BC, Furie B, Beckwith J, Dutton R, Boyd D (2015) Compounds targeting disulfide bond forming enzyme DsbB of Gram-negative bacteria. Nat Chem Biol 11:292-298. doi:10.1038/nchembio.1752

Lasica AM, Jagusztyn-Krynicka EK (2007) The role of Dsb proteins of Gram-negative bacteria in the process of pathogenesis. FEMS Microbiol Rev 31:626-636. doi:10.1111/j.1574-6976.2007.00081.x

Lasica AM, Wyszynska A, Szymanek K, Majewski P, JagusztynKrynicka EK (2010) Campylobacter protein oxidation influences epithelial cell invasion or intracellular survival as well as intestinal tract colonization in chickens. J Appl Genet 51:383-393. doi:10. 1007/BF03208868

Lester J, Kichler S, Oickle B, Fairweather S, Oberc A, Chahal J, Ratnayake D, Creuzenet C (2015) Characterization of Helicobacter pylori HP0231 (DsbK): role in disulfide bond formation, redox homeostasis and production of Helicobacter cystein-rich protein HcpE. Mol Microbiol. doi:10.1111/mmi.12923

Letley DP, Rhead JL, Bishop K, Atherton JC (2006) Paired cysteine residues are required for high levels of the Helicobacter pylori autotransporter VacA. Microbiology 152:1319-1325. doi:10.1099/ mic. $0.28548-0$

Leverrier P, Declercq JP, Denoncin K, Vertommen D, Hiniker A, Cho SH, Collet JF (2011) Crystal structure of the outer membrane protein RcsF, a new substrate for the periplasmic protein-disulfide isomerase DsbC. J Biol Chem 286:16734-16742. doi:10.1074/jbc.M111. 224865

Lewin A, Crow A, Hodson CT, Hederstedt L, Le Brun NE (2008) Effects of substitutions in the CXXC active-site motif of the extracytoplasmic thioredoxin ResA. Biochem J 414:81-91. doi:10.1042/BJ20080356

Lillington J, Geibel S, Waksman G (2014) Biogenesis and adhesion of type 1 and P pili. Biochim Biophys Acta 1840:2783-2793. doi:10. 1016/j.bbagen.2014.04.021

Lin HH, Tseng LY (2010) DBCP: a web server for disulfide bonding connectivity pattern prediction without the prior knowledge of the bonding state of cysteines. Nucleic Acids Res 38:W503-W507. doi: 10.1093/nar/gkq514

Lin D, Rao CV, Slauch JM (2008) The Salmonella SPI1 type three secretion system responds to periplasmic disulfide bond status via the flagellar apparatus and the RcsCDB system. J Bacteriol 190:87-97. doi:10.1128/JB.01323-07

Lin D, Kim B, Slauch JM (2009) DsbL and DsbI contribute to periplasmic disulfide bond formation in Salmonella enterica serovar Typhimurium. Microbiology 155:4014-4024. doi:10.1099/mic.0. 032904-0

Ling LL, Schneider T, Peoples AJ, Spoering AL, Engels I, Conlon BP, Mueller A, Schaberle TF, Hughes DE, Epstein S, Jones M, Lazarides L, Steadman VA, Cohen DR, Felix CR, Fetterman KA, Millett WP, Nitti AG, Zullo AM, Chen C, Lewis K (2015) A new antibiotic kills pathogens without detectable resistance. Nature 517: 455-459. doi:10.1038/nature14098

Marquez-Chamorro AE, Aguilar-Ruiz JS (2015) Soft computing methods for disulfide connectivity prediction. Evol Bioinformatics Online 11:223-229. doi:10.4137/EBO.S25349

McCarthy AA, Haebel PW, Torronen A, Rybin V, Baker EN, Metcalf P (2000) Crystal structure of the protein disulfide bond isomerase, DsbC, from Escherichia coli. Nat Struct Biol 7:196-199. doi:10. $1038 / 73295$
McMahon RM, Premkumar L, Martin JL (2014) Four structural subclasses of the antivirulence drug target disulfide oxidoreductase DsbA provide a platform for design of subclass-specific inhibitors. Biochim Biophys Acta 1844:1391-1401. doi:10.1016/j.bbapap. 2014.01.013

Messens J, Collet JF, Van Belle K, Brosens E, Loris R, Wyns L (2007) The oxidase DsbA folds a protein with a nonconsecutive disulfide. J Biol Chem 282:31302-31307. doi:10.1074/jbc.M705236200

Miki T, Okada N, Danbara H (2004) Two periplasmic disulfide oxidoreductases, DsbA and SrgA, target outer membrane protein SpiA, a component of the Salmonella pathogenicity island 2 type III secretion system. J Biol Chem 279:34631-34642. doi:10.1074/jbc. M402760200

Moraes TF, Spreter T, Strynadka NC (2008) Piecing together the type III injectisome of bacterial pathogens. Curr Opin Struct Biol 18:258 266. doi:10.1016/j.sbi.2007.12.011

Morgan SJ, French EL, Thomson JJ, Seaborn CP, Shively CA, Krukonis ES (2015) Formation of an Intramolecular Periplasmic disulfide bond in TcpP protects TcpP and TcpH from degradation in Vibrio cholerae. J Bacteriol 198:498-509. doi:10.1128/JB.00338-15

Peek JA, Taylor RK (1992) Characterization of a periplasmic thiol:disulfide interchange protein required for the functional maturation of secreted virulence factors of Vibrio cholerae. Proc Natl Acad Sci U S A 89:6210-6214

Qin A, Zhang Y, Clark ME, Moore EA, Rabideau MM, Moreau GB, Mann BJ (2016) Components of the type six secretion system are substrates of Francisella tularensis Schu S4 DsbA-like FipB protein. Virulence 7:882-894. doi:10.1080/21505594.2016.1168550

Quan S, Schneider I, Pan J, Von Hacht A, Bardwell JC (2007) The CXXC motif is more than a redox rheostat. J Biol Chem 282:28823-28833. doi:10.1074/jbc.M705291200

Ren G, Stephan D, Xu Z, Zheng Y, Tang D, Harrison RS, Kurz M, Jarrott R, Shouldice SR, Hiniker A, Martin JL, Heras B, Bardwell JC (2009) Properties of the thioredoxin fold superfamily are modulated by a single amino acid residue. J Biol Chem 284:10150-10159. doi: 10.1074/jbc.M809509200

Ren G, Champion MM, Huntley JF (2014) Identification of disulfide bond isomerase substrates reveals bacterial virulence factors. Mol Microbiol 94:926-944. doi:10.1111/mmi.12808

Roszczenko P, Radomska KA, Wywial E, Collet JF, Jagusztyn-Krynicka EK (2012) A novel insight into the oxidoreductase activity of Helicobacter pylori HP0231 protein. PLoS One 7:e46563. doi:10. 1371/journal.pone.0046563

Roszczenko P, Grzeszczuk M, Kobierecka P, Wywial E, Urbanowicz P, Wincek P, Nowak E, Jagusztyn-Krynicka EK (2015) Helicobacter pylori HP0377, a member of the Dsb family, is an untypical multifunctional $\mathrm{CcmG}$ that cooperates with dimeric thioldisulfide oxidase HP0231. BMC Microbiol 15:135. doi:10.1186/s12866-015-0471-z

Ruiz N, Chng SS, Hiniker A, Kahne D, Silhavy TJ (2010) Nonconsecutive disulfide bond formation in an essential integral outer membrane protein. Proc Natl Acad Sci U S A 107:12245-12250. doi:10.1073/pnas. 1007319107

Shepherd M, Heras B, Achard ME, King GJ, Argente MP, Kurth F, Taylor SL, Howard MJ, King NP, Schembri MA, McEwan AG (2013) Structural and functional characterization of $\mathrm{ScsC}$, a periplasmic thioredoxin-like protein from Salmonella enterica serovar Typhimurium. Antioxid Redox Signal 19:1494-1506. doi:10. 1089/ars.2012.4939

Shouldice SR, Heras B, Walden PM, Totsika M, Schembri MA, Martin JL (2011) Structure and function of DsbA, a key bacterial oxidative folding catalyst. Antioxid Redox Signal 14:1729-1760. doi:10. 1089/ars.2010.3344

Singh R (2008) A review of algorithmic techniques for disulfide-bond determination. Brief Funct Genomic Proteomic 7:157-172. doi:10. 1093/bfgp/eln008 
Sinha S, Langford PR, Kroll JS (2004) Functional diversity of three different DsbA proteins from Neisseria meningitidis. Microbiology 150:2993-3000. doi:10.1099/mic.0.27216-0

Stirnimann CU, Grutter MG, Glockshuber R, Capitani G (2006a) nDsbD: a redox interaction hub in the Escherichia coli periplasm. Cell Mol Life Sci 63:1642-1648. doi:10.1007/s00018-006-6055-1

Stirnimann CU, Rozhkova A, Grauschopf U, Bockmann RA, Glockshuber R, Capitani G, Grutter MG (2006b) High-resolution structures of Escherichia coli cDsbD in different redox states: a combined crystallographic, biochemical and computational study. J Mol Biol 358:829-845. doi:10.1016/j.jmb.2006.02.030

Sturm N, Jortzik E, Mailu BM, Koncarevic S, Deponte M, Forchhammer K, Rahlfs S, Becker K (2009) Identification of proteins targeted by the thioredoxin superfamily in Plasmodium falciparum. PLoS Pathog 5:e1000383. doi:10.1371/journal.ppat.1000383

Tinsley CR, Voulhoux R, Beretti JL, Tommassen J, Nassif X (2004) Three homologues, including two membrane-bound proteins, of the disulfide oxidoreductase DsbA in Neisseria meningitidis: effects on bacterial growth and biogenesis of functional type IV pili. J Biol Chem 279:27078-27087. doi:10.1074/jbc.M313404200

Turcot I, Ponnampalam TV, Bouwman CW, Martin NL (2001) Isolation and characterization of a chromosomally encoded disulphide oxidoreductase from Salmonella enterica serovar Typhimurium. Can J Microbiol 47:711-721

Ventola CL (2015a) The antibiotic resistance crisis: part 1: causes and threats vol 40,2015/04/11

Ventola CL (2015b) The antibiotic resistance crisis: part 2: management strategies and new agents vol 40, 2015/05/20

Wang G, Alamuri P, Maier RJ (2006) The diverse antioxidant systems of Helicobacter pylori. Mol Microbiol 61:847-860. doi:10.1111/j. 1365-2958.2006.05302.x

Wang X, Dutton RJ, Beckwith J, Boyd D (2011) Membrane topology and mutational analysis of Mycobacterium tuberculosis VKOR, a protein involved in disulfide bond formation and a homologue of human vitamin K epoxide reductase. Antioxid Redox Signal 14: 1413-1420. doi:10.1089/ars.2010.3558

Watarai M, Tobe T, Yoshikawa M, Sasakawa C (1995) Disulfide oxidoreductase activity of Shigella flexneri is required for release of Ipa proteins and invasion of epithelial cells. Proc Natl Acad Sci U S A 92:4927-4931

Wells TJ, Tree JJ, Ulett GC, Schembri MA (2007) Autotransporter proteins: novel targets at the bacterial cell surface. FEMS Microbiol Lett 274:163-172. doi:10.1111/j.1574-6968.2007.00833.x

WHO (2014) Antimicrobial resistance: global report on surveillance 2014.

Williamson JA, Cho SH, Ye J, Collet JF, Beckwith JR, Chou JJ (2015) Structure and multistate function of the transmembrane electron transporter CcdA. Nat Struct Mol Biol 22:809-814. doi:10.1038/ nsmb.3099

Yu J, Kaper JB (1992) Cloning and characterization of the eae gene of enterohaemorrhagic Escherichia coli O157:H7. Mol Microbiol 6: 411-417

Zhong Y, Anderl F, Kruse T, Schindele F, Jagusztyn-Krynicka EK, Fischer W, Gerhard M, Mejias-Luque R (2016) Helicobacter pylori HP0231 influences bacterial virulence and is essential for gastric colonization. PLoS One 11:e0154643. doi:10.1371/journal.pone. 0154643

Zhou Y, Cierpicki T, Jimenez RH, Lukasik SM, Ellena JF, Cafiso DS, Kadokura H, Beckwith J, Bushweller JH (2008) NMR solution structure of the integral membrane enzyme DsbB: functional insights into DsbB-catalyzed disulfide bond formation. Mol Cell 31: 896-908. doi:10.1016/j.molcel.2008.08.028

Zipperer A, Konnerth MC, Laux C, Berscheid A, Janek D, Weidenmaier C, Burian M, Schilling NA, Slavetinsky C, Marschal M, Willmann M, Kalbacher H, Schittek B, Brotz-Oesterhelt H, Grond S, Peschel A, Krismer B (2016) Human commensals producing a novel antibiotic impair pathogen colonization. Nature 535:511-516. doi:10. 1038/nature18634 